\title{
Optimal management of dactylitis in patients with psoriatic arthritis
}

This article was published in the following Dove Press journal:

Open Access Rheumatology: Research and Reviews

18 September 2015

Number of times this article has been viewed

\section{Toshiyuki Yamamoto \\ Department of Dermatology, Fukushima Medical University, Fukushima, Japan}

Correspondence: Toshiyuki Yamamoto Department of Dermatology, Fukushima Medical University, Hikarigaoka I,

Fukushima 960-1295, Japan

$\mathrm{Tel}+8 \mid 24547$ I 307

Fax +8| 24547 I 307

Email toyamade@fmu.ac.jp

\begin{abstract}
Psoriatic arthritis (PsA) is an inflammatory arthropathy associated with cutaneous psoriasis, which is currently classified as a seronegative spondyloarthropathy. The presence of cutaneous psoriasis is important for correct and early diagnosis of PsA, because the onset of cutaneous lesions usually precedes the appearance of joint manifestation. Thus, dermatologists are able to detect the condition at its inception. PsA has several unique characteristics such as enthesopathy, dactylitis, and abnormal bone remodeling. In particular, dactylitis occurs on the easily observed sites such as digits, and is thus a significant indicator of PsA. It is important to observe not only the fingers but also the toes, because dactylitis involves both digits of the hands and feet. Recently, new ideas regarding the involvement of the interleukin (IL)-23/Th17 axis have emerged, and the dramatic effects of targeting therapies have highlighted the physiological roles of key cytokines such as tumor necrosis factor- $\alpha$, IL-17A, and IL-23 in psoriasis. As recent insights are shedding light on the pathogenesis of PsA, understanding of the pathogenesis of dactylitis and enthesitis are also progressing. In this article, current views on the optimal management of dactylitis are discussed.
\end{abstract}

Keywords: pathogenesis, therapy, enthesitis, tenosynovitis

\section{Introduction}

Psoriatic arthritis (PsA) is a chronic inflammatory arthropathy associated with psoriasis. Although most patients with PsA have moderate to severe skin disease, ${ }^{1}$ the severity of cutaneous psoriasis varies from subtle (sine psoriasis) to erythrodermic conditions. PsA is currently classified as a seronegative spondyloarthropathy, characterized by cutaneous psoriasis, joint destruction, and extra-articular lesions involving the eye, gut, and bowel. Psoriasis is mediated by aberrant, skin-directed T-cells, especially Th1/Th17 subsets, in the pathogenesis. Interleukin (IL)-23 secreted by tumor necrosis factor (TNF)- $\alpha$ and inducible nitric oxide synthase-producing dendritic cells leads to activation and proliferation of Th17 cells from CD4+ naïve T-cells. The Th17 subsets release IL-17 and IL-22, which promote neutrophil recruitment and keratinocyte hyperproliferation, respectively. Although a number of studies have implicated some genetic, environmental, and immunological factors in the pathogenesis of PsA, its etiology has not yet been fully elucidated compared with psoriasis.

Dermatologists are the first line to detect early PsA because skin lesions precede the onset of joint manifestation in nearly $80 \%$ of cases. Furthermore, a large number of psoriatic patients are newly diagnosed with PsA, if they are reevaluated with much attention to joint lesions. ${ }^{2,3}$ Several comprehensive reviews of PsA have also been indicated from a dermatological perspective. ${ }^{4-7}$ There are several signs of suspected PsA, one of which is dactylitis. Dactylitis is clinically diagnosed and is an important 
indicator of PsA. Moreover, treatment of dactylitis is required because it progresses if it goes untreated. Herein, the optimal management of dactylitis associated with PsA is discussed.

\section{Clinical features of PsA}

Joint manifestations of PsA were classically defined by the criteria of Moll and Wright ${ }^{8}$ into asymmetric oligoarticular arthritis, symmetric polyarthritis, distal interphalangeal (DIP) predominant, arthritis mutilans, and spondylitis types. However, PsA exhibits a wide range of clinical presentations, which cannot be clearly subdivided into those five groups. In addition, sometimes, there is switching between phenotypes during the clinical courses. Although several variants or modified criteria have been proposed since Moll and Wright's classification, ${ }^{9-12}$ the recently published set of classification criteria for PsA (CASPAR) has been widely adopted. ${ }^{13}$ According to these criteria, however, PsA may be diagnosed even in the absence of cutaneous psoriasis. Furthermore, psoriasis sometimes assumes clinical appearances close to other diseases such as nummular eczema, asteatotic eczema, chronic eczema, contact dermatitis, seborrheic dermatitis, mycosis fungoides, sarcoidosis, and so on. Therefore, the role of dermatologists is essential.

Other forms of arthritis, such as rheumatoid arthritis (RA), osteoarthritis, reactive arthritis, ankylosing spondylitis, etc, should be differentiated; however, this can sometimes be difficult. RA is most common in females, while PsA affects males and females almost equally. Although PsA also shows progressive peripheral joint destruction, the joints are less tender and swollen than those in patients with RA. In addition, the distribution in PsA cases tends to be asymmetrical and oligoarticular, and DIP joint involvement is more common than in RA cases. The affected joints show a "ray" distribution involving all three joints of the affected digit in PsA, whereas the joints at the same level are affected in RA. In addition to joint pain, back involvement is another important manifestation that should be noted at clinical examination, which is observed in at least $40 \%$ of patients with PsA. ${ }^{14}$ Unlike RA, morning stiffness is detected in 50\% of PsA patients. ${ }^{15}$ Differentiation with osteoarthritis and distal type PsA is also sometimes difficult. Other important clinical manifestations characteristic of PsA include the presence of nail and cutaneous psoriasis and dactylitis.

Although patients with severe cutaneous psoriasis in general also develop arthralgia, the severity of the skin lesions does not always correlate with the presence of joint lesions. For example, some patients with PsA develop severe plaquetype psoriasis and occasionally erythroderma, whereas psoriatic lesions in others are faint or wholly absent (sine psoriasis). ${ }^{16,17}$ Conversely, it is frequent that patients with severe cutaneous psoriasis may lack arthralgia.

Nail psoriasis presents with various changes, ie, pitting, deformation, onycholysis, thickening of the nail plate, subungual hyperkeratosis, and longitudinal/transverse lines. Compared with psoriasis vulgaris, PsA patients have been reported to display a higher incidence of nail lesions. ${ }^{16,18-21}$ Nail involvement is almost always seen in cases of distal type PsA ${ }^{18}$ due to the close anatomical relationship between DIP joints and nail matrix. Nails are functionally integrated with the enthesis associated with the distal phalanx that provides anchorage to the nail and DIP joints via bridging tendons. Thus, the DIP nail-enthesis apparatus offers a novel perspective on PsA. ${ }^{22}$ In cases where inflammatory arthritis involves the DIP joints or where psoriatic skin involves the nail matrix, nail changes are frequently observed. Retrospective cohort studies showed that patients with psoriatic lesions on the nail, scalp, and intergluteal/ perianal regions are significantly likely to develop arthritides in due course. ${ }^{23}$ By contrast, other studies have denied any significant predictive locations of psoriasis for the development of arthritis. ${ }^{24}$ Further prospective investigation is needed to determine whether nail, scalp, and perianal psoriasis are definitely associated with future development of arthritides. A recent investigation in the collaboration between dermatology and rheumatology has demonstrated that examination by ultrasonography of the nails can detect early or occult PsA. ${ }^{25}$

\section{Dactylitis}

Although it is seen in not only PsA but also other diseases such as sarcoidosis, tuberculosis, and gout, dactylitis is one of the characteristic symptoms of PsA with a high specificity (Figure 1). Dactylitis is clinically presented with sausagelike swelling of the digit, and is included in the CASPAR criteria as one of the hallmarks of PsA. Fingers and toes are involved and are presented with swelling, slight redness, and deformity. Dactylitis has been thought to be a result of the concomitant swelling and inflammation of the flexor tendon sheaths of the metacarpophalangeal, metatarsophalangeal, or interphalangeal joints. ${ }^{26}$ Flexor tenosynovitis can be detected by examination with magnetic resonance imaging (MRI) and ultrasonography. Furthermore, dactylitis is associated with radiologically evident erosive damage to the joints. ${ }^{27}$

A recent survey of 752 patients with PsA showed that 294 patients had dactylitis, a prevalence of $39 \% .{ }^{28}$ 


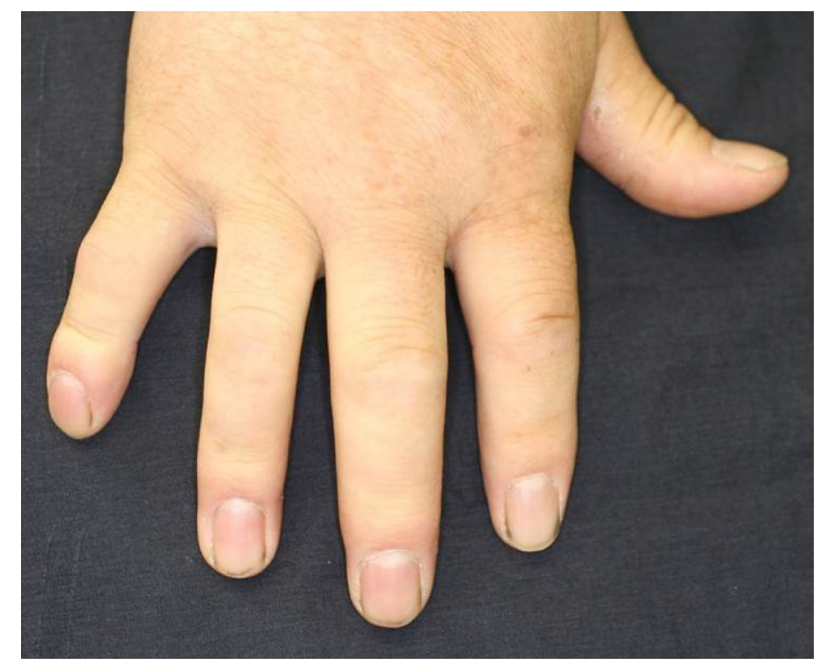

Figure I Dactylitis of the second and third fingers.

Moreover, dactylitis is frequently seen in spondyloarthritis other than PsA, and 59 patients (21.5\%) suffered from dactylitis among 275 spondyloarthritis patients. ${ }^{29}$ In the studies, toes were more frequently involved than fingers (78\% vs $42 \%$ ) in dactylitis, and the second digit was the most frequent. The digital swelling was an inaugural symptom in 10\% (5/49) in PsA, and more than half of the patients with dactylitis had the first episode of dactylitis before the diagnosis of spondyloarthritis. ${ }^{29}$ Dactylitis progresses in association with disease severity (Figure 2), even if treated with nonsteroidal anti-inflammatory drugs (NSAIDs) or disease-modifying anti-rheumatic drugs (DMARDs). Therefore, early therapeutic intervention is needed.

\section{Evaluation methods}

It is difficult to make an objective score for the severity or extent of dactylitis, and various methods have so far been used. The representative evaluation is the Leeds Dactylitis Index, which examines the 20 digits with a tenderness score $(0=$ no tenderness, $1=$ tender, $2=$ tender and winces, and $3=$ tender and withdrawal), and its simplified version (either $1=$ presence or $0=$ absence). On the other hand, the Leeds Dactylitis Instrument, also known as a dactylometer or circumferometer, was also developed for objective and validated evaluation of dactylitis. ${ }^{30,31}$

\section{Role of dermatologists for early detection of PsA}

It is quite important to detect PsA early because joint damage occurs and progresses in the early course of the disease. The "early" stage of PsA is usually used for patients with a duration of less than 2 years. ${ }^{32,33}$ Dermatologists are uniquely poised to suspect PsA, which may lead to its early diagnosis, because cutaneous lesions precede the onset of joint pain in nearly $70 \%$ of patients. However, dermatologists may easily overlook PsA because, in general, little attention is paid to
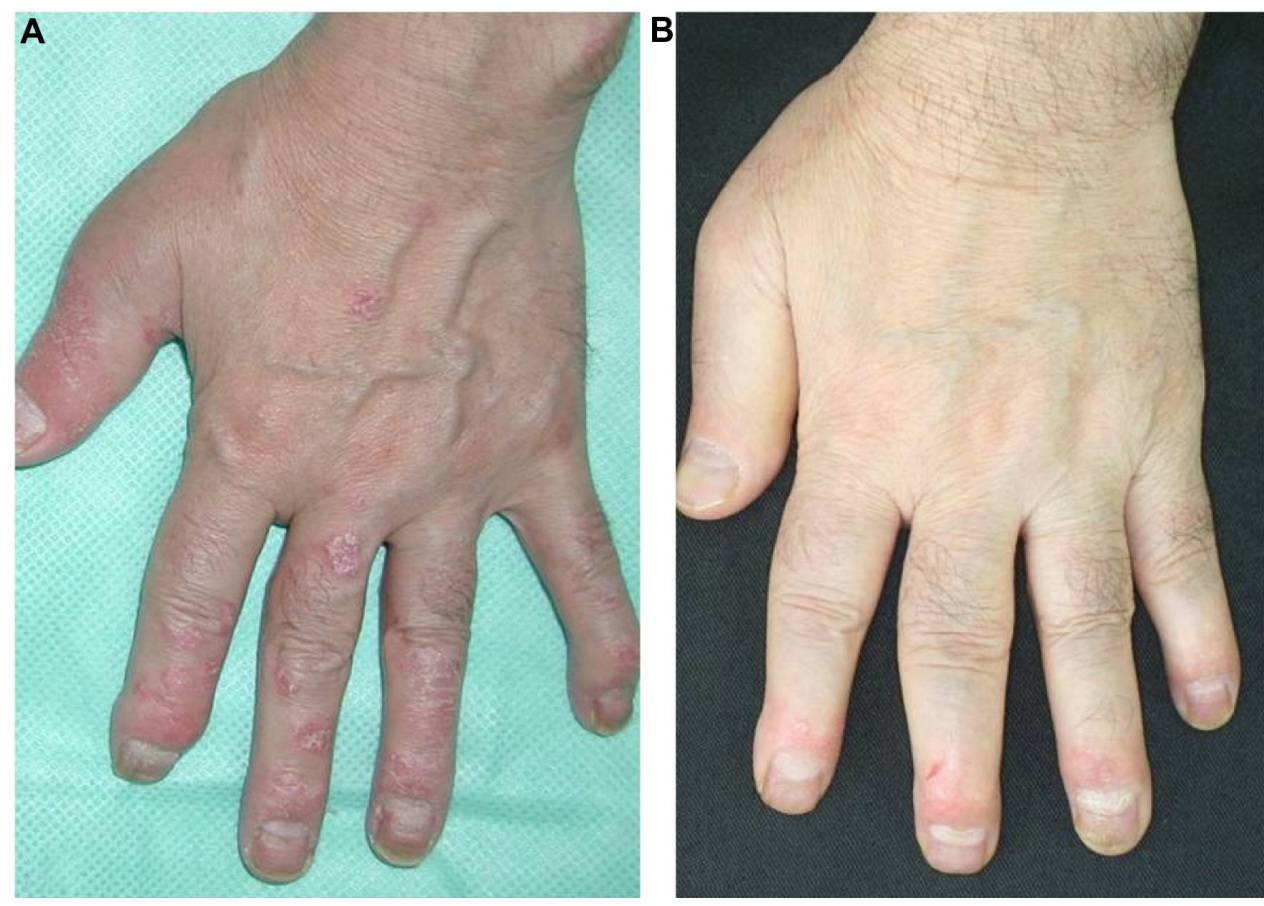

Figure 2 Progression of dactylitis.

Notes: Development of marked dactylitis (B) 8 years later in the same patient (A). 
the joint manifestations. Recent studies have demonstrated that a high prevalence of undiagnosed psoriasis patients were newly diagnosed with PsA, if they were reevaluated with specific focus on joint manifestations. It is thus suggested that early diagnosis becomes more possible if the dermatologist pays the requisite attention to the arthritic symptoms. Examination by ultrasonography and MRI are recommended for their sensitivity, ${ }^{34,35}$ which is an advantage over conventional radiography in the evaluation of enthesopathy. Another useful method for screening is to utilize questionnaire forms. So far, several screening tools have been developed such as Toronto Psoriatic Arthritis Screening tools (ToPAS), Psoriasis Epidemiology Screening Tool (PEST), Psoriatic Arthritis Screening and Evaluation (PASE), which have high sensitivity and specificity. ${ }^{36}$

\section{Enthesitis}

Enthesitis or enthesopathy is defined as inflammation at the site of the attachment of tendons, ligaments, or joint capsules to the bones. Even if it is clinically silent, enthesitis can occasionally be observed on examination by MRI. In contrast to RA, enthesis may be a primary target lesion in PsA. Recently, the concept of a synovio-entheseal complex was proposed, which views the enthesis, the adjacent cartilage, periosteum, and the synovial and bursa membranes together as if it is a unique organ. ${ }^{37}$ This concept may correspond to the synovio-cartilage junction in RA. The enthesis is susceptible to repetitive mechanical stress and minor injury due to environmental risk factors, which may trigger joint inflammation ${ }^{38}$ known as the "deep Koebner" phenomenon or "joint Koebnerization". The concept is attractive, but in the clinical settings, patients with PsA do not always engage in physical work, and further, half of the patients are females, many of whom are housewives. Previous studies have detected several significant factors in association with PsA, such as mental stress, rubella vaccination, oral corticosteroid, injury, recurrent oral ulcers, and removal work. ${ }^{39}$

Analysis of the inflammatory cell subsets by immunohistochemistry have shown that cellular infiltrates are predominantly composed of CD8+ T-cells in the edematous entheses, ${ }^{40}$ suggesting an important role for a HLA-class I (ie, HLA-B27)-mediated immune response with cytotoxic T-cells as effector lymphocytes. CD8+ cells recognize HLAclass I antigens, and may play a key role in local inflammation of the enthesitis of PsA. In a murine model, IL-23 activates resident T-cells within the enthesis, which differentiate Th17 subsets secreting IL-22 and IL-17. ${ }^{41}$ Of interest, IL-22 and
IL-17 have opposite effects, such as osteoproliferation and bone loss, respectively.

\section{Dactylitis and enthesitis}

Although the mechanisms of induction of dactylitis are still unclear, tenosynovitis with soft tissue involvement has been traditionally considered to be the cause of dactylitis. Furthermore, other studies have reported that dactylitis is not just a result of disease of the tenosynovium, but is also associated with erosive joint damage. ${ }^{29}$ Recent studies have suggested that enthesitis is common in PsA dactylitis by MRI examination, and that enthesopathy related to the flexor tendon pulleys and fibrous sheaths may associate with flexor tenosynovitis. ${ }^{42}$ Pulleys are sites frequently under friction against bone, which may lead to inflammation as a result of the deep Koebner phenomenon. Those inflammatory changes at digital pulleys and tendons are suggested to induce "functional" enthesitis in dactylitis. ${ }^{42}$ A mouse model for PsA suggested that in dactylitis-like swelling, the changes at insertions occur prior to adjacent tissues. ${ }^{43} \mathrm{~A}$ possible mechanism of dactylitis is shown in Figure 3.

\section{Synovial tissue}

Synovial biopsy is less frequently performed in PsA, and thus the pathophysiology of the psoriatic synovium has not been fully elucidated compared with RA. Although several reviews have been published, ${ }^{44,45}$ detailed analyses of the PsA synovium matching the sites, comparing the disease stages,

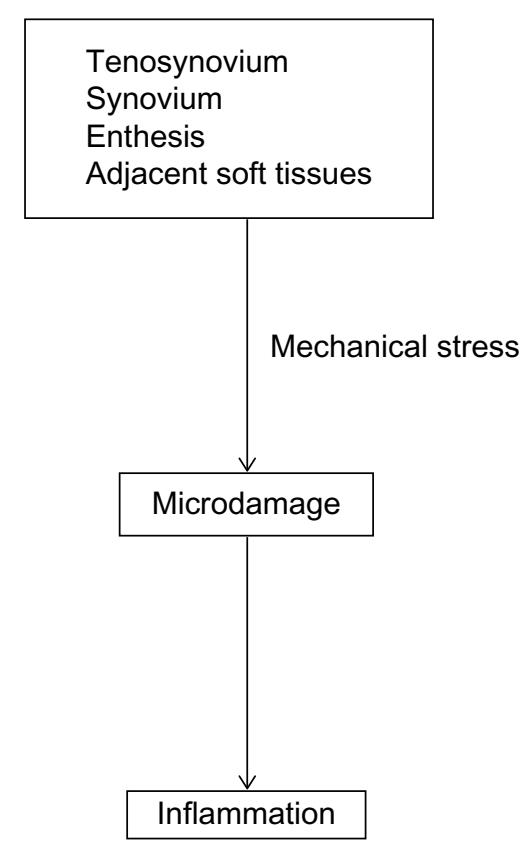

Figure 3 Possible mechanism of dactylitis. 
etc, are scarce. In general, the changes in the synovium, such as proliferation, lining thickness, and cellular infiltrates, are less pronounced than in RA pannus, while vascularity and polymorphonuclear leukocytic infiltrates are more pronounced in the synovium of PsA patients. ${ }^{46,47}$ Functionally active T-cells, both CD4+ and CD8+ with clonal or oligoclonal expansions, are abundantly infiltrated in the synovial tissues of PsA, ${ }^{48}$ most of which are activated memory T-cells expressing HLA-DR and CD45RO. ${ }^{49}$ CLA-positive T-cells are also recruited to the synovium.

Other studies have shown that CD8+ T-cells are significantly increased with clonal expansions in synovial fluids, whereas CD4+ T-cells are few. ${ }^{48,50}$ T-cell-derived cytokines such as IL-1 $\beta$, IL-2, IL-10, interferon- $\gamma($ IFN- $\gamma$ ), and TNF- $\alpha$ are dominantly detected in the synovium. ${ }^{51,52}$ In addition, concentration of IL-17 is also elevated in the synovial fluids. IL-17 is secreted by neutrophils and mast cells, and IL-17-positive mast cells in particular, which are increased in number is psoriatic synovium, contribute to the synovial inflammation. ${ }^{53}$ Furthermore, in vitro studies have suggested the significance of functionally active IL-17 receptors in the PsA synovium. ${ }^{54}$ Besides IFN- $\gamma$ and TNF- $\alpha$, Th17 cells secrete IL-6, IL-21, and IL-22. IL-22 enhances the expression of MMP-1 and MMP-3. ${ }^{55}$ Other than lymphocytes, increases in the number of infiltrating macrophages, dendritic cells, mast cells, and neutrophils are also seen in the psoriatic synovium. In particular, neutrophils play an important role in the lesional psoriatic skin (Munro's microabscess), and their infiltration is also seen in the synovium. Recent findings suggest that sources of IL-17 are not only helper T-cells, but also $\gamma \delta$ T-cells, neutrophils, and mast cells. ${ }^{56}$

Angiogenesis in the synovium leads to proliferation of synovial tissues of PsA. Expression of angiogenic cytokines such as vascular endothelial growth factor, transforming growth factor- $\beta$, and angiopoietins is detected in the psoriatic synovium, especially in the early stages. ${ }^{57}$ In addition, new molecules involved in angiogenesis such as angiopoietin, Tie, and hypoxia-inducible factor- $1 \alpha$ are also detected. ${ }^{58}$ High levels of TNF- $\alpha$ are found in the synovial fluids and synovial membrane of PsA, ${ }^{59-61}$ which upregulates angiogenic cytokines and MMP. ${ }^{62}$ In addition, TNF- $\alpha$ enhances endothelial cells to express adhesion molecules, such as intercellular adhesion molecule-1, vascular cell adhesion molecule-1, and E-selectin, ${ }^{63}$ which promote leukocyte migration to the inflammatory sites.

\section{Bone}

A unique radiographic change of PsA is dysregulated (altered) bone remodeling characterized by both extensive bone erosion and exaggerated bone formation in a single patient. New bone formation is an item included in the CASPAR criteria. T-cells and synovial fibroblasts support osteoclastogenesis through receptor activator of nuclear factor-kappa B ligand (RANKL), TNF- $\alpha$, and IL-7. ${ }^{64}$ RANKL and IL-1 in the synovium-bone interface may also mediate aggressive bone resorption. ${ }^{65}$ In the PsA synovium, RANKL is strongly expressed in the synovial fibroblasts, opposite to the expression of osteoprotegerin, an antagonist of RANKL. ${ }^{65}$ IL-23 promotes osteoclast formation and bone destruction indirectly via IL-17, by inducing IL-1, TNF- $\alpha$, and RANKL expression, ${ }^{66}$ or even without IL-17 involvement. ${ }^{67}$ Another possible mediator inhibiting bone formation is sclerostin, an endogenous mediator which antagonizes bone morphogenetic protein (BMP) and negatively regulates bone formation and osteoblast differentiation, and promotes osteoblast apoptosis. ${ }^{68}$ Dickkopf-related protein 1 (DKK-1) is also a Wnt inhibitor, which inhibits osteoblast function. ${ }^{69} \mathrm{DKK}-1$ is also induced by TNF signaling. ${ }^{69}$ By contrast, BMPs are required for the formation of new bone, and osteoblasts differentiate from the mesenchymal cell lineage via the signaling pathways such as Wnt- $\beta$ catenin. ${ }^{70}$ Many biologics have modes of action of not only suppression of inflammation but also inhibition of differentiation of osteoclasts from precursor cells, ${ }^{71}$ which may contribute to the bone manifestation.

\section{Therapy}

Dactylitis has been treated with NSAIDs, DMARDs, and recently biologics. Sulfasalazine, methotrexate, cyclosporine, and leflunomide have been used as DMARDs so far. Compared with biologics, DMARDs alone are mildly effective and do not result in significant effects. ${ }^{72}$ Very recently, a systematic review of therapies for dactylitis showed that out of the 29 trials, 18 were randomized controlled trials with crossover designs at 12-24 weeks, one was a prospective cohort study, one was a prospective case-control study, and the remaining nine were open-label studies. ${ }^{73}$

Among 252 patients with acute dactylitis, $77 \%$ of patients responded to biologics at 6 months, whereas 51\% responded to DMARDs. ${ }^{28}$ At 12 months, $87 \%$ of patients responded to biologics, whereas $70 \%$ responded to DMARDs. According to the recommendation by Group for Research and Assessment of Psoriasis and Psoriatic Arthritis (GRAPPA), NSAIDs are initially used for dactylitis. For resistant cases, anti-TNF drugs should be considered..$^{74}$ Dactylitis is greatly improved by biologics in many cases (Figure 4). Adalimumab treatment resulted in greater improvement than placebo, but without statistical significance. ${ }^{75}$ Infliximab is effective for dactylitis, and a significant 

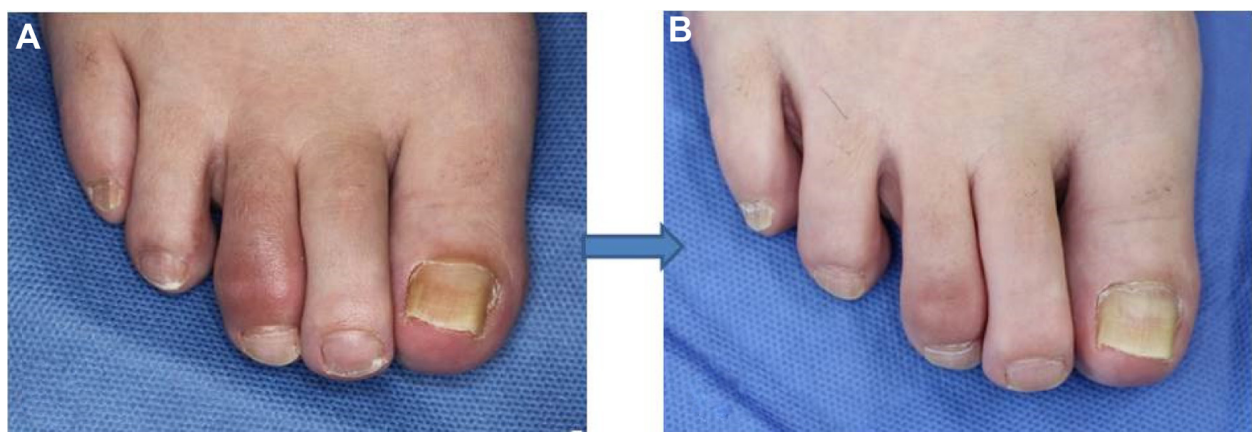

Figure 4 Marked improvement of dactylitis after adalimumab therapy.

Notes: (A) Pre-treatment; (B) after 3 times' administration of adalimumab.

effect on dactylitis was achieved in IMPACT studies. ${ }^{76}$ However, mean baseline dactylitis scores were low, and the number of evaluated digits was small. In patients treated with golimumab, the $100 \mathrm{mg}$ treated group showed an $83 \%$ change from baseline and the $50 \mathrm{mg}$ treated group showed a $70 \%$ change, whereas a $57 \%$ change was observed in the placebo group. ${ }^{77}$ By ustekinumab therapy, significantly greater improvements in dactylitis were achieved with both $45 \mathrm{mg}$ and $90 \mathrm{mg}$ doses, as compared with placebo. ${ }^{78}$ Treatments with secukinumab, an anti-IL-17A monoclonal antibody, lead to only minimal improvement of dactylitis, by Leeds Dactylitis Index scores. ${ }^{79}$ Regarding the oral phosphodiesterase 4 inhibitor, apremilast, the mean change from baseline severity score resulted in a superior effect as compared with treatment with placebo; however, the difference did not reach statistical significance at week $24 .^{80}$

\section{Conclusion}

Along with recent progress in our understanding of the pathogenesis of PsA and entry of effective new therapies into clinical settings, we can more reliably make correct diagnoses and initiate early therapeutic interventions. It is now well-known that current biologics are beneficial to ameliorating joint manifestations, cutaneous and nail psoriasis, as well as dactylitis and enthesitis. Overall, the evidence and statistical difference of the efficacy of biologics for dactylitis may not be high, which may depend on the method of evaluation and also the number of subject digits. Nevertheless, acute dactylitis responds to therapy and thus early intervention is able to induce and also maintain remission. It is important to diagnose PsA as well as dactylitis, and intervene early with biologics. Additionally, studies on the effectiveness of switching therapies in TNF-irresponsive dactylitis and enthesitis are required. Hopefully, more novel and effective therapies targeting more specific molecules will be available in the future. We should aim for a deeper understanding of the mechanisms and optimal management of dactylitis.

\section{Disclosure}

The author reports no conflicts of interest in this work.

\section{References}

1. Gelfand JM, Gladman DD, Mease PJ, et al. Epidemiology of psoriatic arthritis in the population of the United States. J Am Acad Dermatol. 2005;53:573-577.

2. Radtke MA, Reich K, Blome C, Rustenbach S, Augustin M. Prevalence and clinical features of psoriatic arthritis and joint complaints in 2009 patients with psoriasis: results of a German national survey. J Eur Acad Dermatol Venereol. 2009;23:683-691.

3. Reich K, Krüger K, Mössner R, Augustin M. Epidemiology and clinical pattern of psoriatic arthritis in Germany: a prospective interdisciplinary epidemiological study of 1511 patients with plaque-type psoriasis. Br J Dermatol. 2009;160:1040-1047.

4. Laws P, Barton A, Warren RB. Psoriatic arthritis - what the dermatologist needs to know. J Eur Acad Dermatol Venereol. 2010;24: 1270-1277.

5. Snyder RA. Psoriatic arthritis: a dermatologist's perspective. Am J Clin Dermatol. 2010;11 Suppl 1:19-22.

6. Yamamoto T. Psoriatic arthritis: from a dermatological perspective. Eur J Dermatol. 2011;21:660-666.

7. Chang CA, Gottlieb AB, Lizzul PF. Management of psoriatic arthritis from the view of the dermatologist. Nat Rev Rheumatol. 2011;7: 588-598.

8. Moll JM, Wright V. Psoriatic arthritis. Semin Arthritis Rheum. 1973;3: $55-78$.

9. Dougados M, van der Linden S, Juhlin R, et al. The European Spondylarthropathy Study Group preliminary criteria for the classification of spondylarthropathy. Arthritis Rheum. 1991;34:1218-1227.

10. Veale D, Rogers S, Fitzgerald O. Classification of clinical subsets in psoriatic arthritis. Br J Rheumatol. 1994;33:133-138.

11. McGonagle D, Conaghan PG, Emery P. Psoriatic arthritis: a unified concept twenty years. Arthritis Rheum. 1999;42:1080-1086.

12. Ruzicka T. Psoriatic arthritis. New types, new treatments. Arch Dermatol. 1996;132:215-219.

13. Taylor W, Gladman D, Helliwell P, et al. Classification criteria for psoriatic arthritis: development of new criteria from a large international study. Arthritis Rheum. 2006;54:2665-2673.

14. Gladman DD. Psoriatic arthritis. Rheum Dis Clin North Am. 1998;24: 829-844.

15. Gladman DD. Psoriatic arthritis. Dermatol Ther. 2009;22:40-55.

16. Cohen MR, Reda DJ, Clegg DO. Baseline relationships between psoriasis and psoriatic arthritis: analysis of 221 patients with active psoriatic arthritis. Department of Veterans Affairs Cooperative Study Group on Seronegative Spondyloarthropathies. J Rheumatol. 1999;26: $1752-1756$ 
17. Scarpa R, Cosentini E, Manguso F, et al. Clinical and genetic aspects of psoriatic arthritis "sine psoriasis". J Rheumatol. 2003;30: 2638-2640.

18. Jones SM, Armas JB, Cohen MG, Lovell CR, Evison G, McHugh NJ. Psoriatic arthritis: outcome of disease subsets and relationship of joint disease to nail and skin disease. $\mathrm{Br} J$ Rheumatol. 1994;33: 834-839.

19. Jiaravuthisan MM, Sasseville D, Vender RB, Murphy F, Muhn CY. Psoriasis of the nail: anatomy, pathology, clinical presentation, and a review of the literature on therapy. J Am Acad Dermatol. 2007;57:1-27.

20. McGonagle D, Benjamin M, Tan AL. The pathogenesis of psoriatic arthritis and associated nail disease: not autoimmune after all? Curr Opin Rheumatol. 2009;21:340-347.

21. Augustin M, Reich K, Blome C, Schäfer I, Laass A, Radtke MA. Nail psoriasis in Germany: epidemiology and burden of disease. Br J Dermatol. 2010;163:580-585.

22. McGonagle D, Tan AL, Benjamin M. The nail as a musculoskeletal appendage - implications for an improved understanding of the link between psoriasis and arthritis. Dermatology. 2009;218:97-102.

23. Wilson FC, Icen M, Crowson CS, McEvoy MT, Gabriel SE, Kremers HM. Incidence and clinical predictors of psoriatic arthritis in patients with psoriasis: a population-based study. Arthritis Rheum. 2009;61: 233-239.

24. Rouzaud M, Sevrain M, Villani AP, et al. Is there a psoriasis skin phenotype associated with psoriatic arthritis? Systematic literature review. J Eur Acad Dermatol Venereol. 2014;28 Suppl 5:17-26.

25. Ash ZR, Tinazzi I, Gallego CC, et al. Psoriasis patients with nail disease have a greater magnitude of underlying systemic subclinical enthesopathy than those with normal nails. Ann Rheum Dis. 2012;71:553-556.

26. Olivieri I, Padula A, Scarano E, Scarpa R. Dactylitis or "sausageshaped" digit. J Rheumatol. 2007;34:1217-1222.

27. Brockbank JE, Stein M, Schentag CT, Gladman DD. Dactylitis in psoriatic arthritis: a marker for disease severity? Ann Rheum Dis. 2005;64: 188-190

28. Gladman DD, Ziouzina O, Thavaneswaran A, Chandran V. Dactylitis in psoriatic arthritis: prevalence and response to therapy in the biologic era. J Rheumatol. 2013;40:1357-1359.

29. Payet J, Gossec L, Paternotte S, et al. Prevalence and clinical characteristics of dactylitis in spondylarthritis: a descriptive analysis of 275 patients. Clin Exp Rheumatol. 2012;30:191-196.

30. Helliwell PS, Firth J, Ibrahim GH, Melsom RD, Shah I, Turner DE Development of an assessment tool for dactylitis in patients with psoriatic arthritis. J Rheumatol. 2005;32:1745-1750.

31. Ferguson EG, Coates LC. Optimisation of rheumatology indices: dactylitis and enthesitis in psoriatic arthritis. Clin Exp Rheumatol. 2014;32: S113-S117.

32. Kane D, Stafford L, Bresnihan B, FitzGerald O. A prospective, clinical and radiological study of early psoriatic arthritis: an early synovitis clinic experience. Rheumatology (Oxford). 2003;42:1460-1468.

33. Olivieri I, D'Angelo S, Padula A, Palazzi C. The challenge of early diagnosis of psoriatic arthritis. J Rheumatol. 2008;35:3-5.

34. Scarpa R, Atteno M, Costa L, et al. Early psoriatic arthritis. J Rheumatol Suppl. 2009;83:26-27.

35. Gisondi P, Tinazzi I, Del Giglio M, Girolomoni G. The diagnostic and therapeutic challenge of early psoriatic arthritis. Dermatology. 2010; 221 Suppl 1:6-14.

36. Boehncke WH, Kirby B, FitzGerald O, van de Kerkhof PC. New development in our understanding of psoriatic arthritis and their impact on the diagnosis and clinical management of the disease. J Eur Acad Dermatol Venereol. 2014;28:264-270.

37. McGonagle D, Lories RJ, Tan AL, Benjamin M. The concept of a "synovio-entheseal complex" and its implications for understanding joint inflammation and damage in psoriatic arthritis and beyond. Arthritis Rheum. 2007;56:2482-2491.

38. Olivieri I, Padula A, D'Angelo S, Scarpa R. Role of trauma in psoriatic arthritis. J Rheumatol. 2008;35:2085-2087.
39. Pattison E, Harrison BJ, Griffiths CE, Silman AJ, Bruce IN Environmental risk factors for the development of psoriatic arthritis: results from a case-control study. Ann Rheum Dis. 2008;67:672-676.

40. Laloux L, Voisin MC, Allain J, et al. Immunohistological study of entheses in spondyloarthropathies: comparison in rheumatoid arthritis and osteoarthritis. Ann Rheum Dis. 2001;60:316-321.

41. Sherlock JP, Joyce-Shaikh B, Turner SP, et al. IL-23 induces spondyloarthropathy by acting on ROR- $\gamma \mathrm{t}+\mathrm{CD} 3+\mathrm{CD} 4-\mathrm{CD} 8$ - entheseal resident $\mathrm{T}$ cells. Nat Med. 2012;18:1069-1076.

42. Tan AL, Fukuba E, Halliday NA, Tanner SF, Emery P, McGonagle D. High-resolution MRI assessment of dactylitis in psoriatic arthritis shows flexor tendon pulley and sheath-related enthesitis. Ann Rheum Dis. 2015;74:185-189.

43. Lories RJ, Matthys P, de Vlam K, Derese I, Luyten FP. Ankylosing enthesitis, dactylitis, and onychoperiostitis in male DBA/1 mice: a model of psoriatic arthritis. Ann Rheum Dis. 2004;63:595-598.

44. Boyle DL, Kavanaugh A. The pathobiology of psoriatic synovium. Curr Opin Rheumatol. 2008;20:404-407.

45. Yamamoto T. Pathophysiology of synovium of psoriatic arthritis. J Clin Dermatol. 2010;1.

46. Kruithof E, Baeten D, De Rycke L, et al. Synovial histopathology of psoriatic arthritis, both oligo- and poly-articular, resembles spondyloarthropathy more than it does rheumatoid arthritis. Arthritis Res Ther 2005; 7:R569-R580.

47. Baeten D, Kruithof E, De Rycke L, et al. Infiltration of the synovial membrane with macrophage subsets and polymorphonuclear cells reflects global disease activity in spondyloarthropathy. Arthritis Res Ther. 2005;7:R359-R369.

48. Costello PJ, Winchester RJ, Curran SA, et al. Psoriatic arthritis joint fluids are characterized by CD8 and CD4 T cell clonal expansions appear antigen driven. J Immunol. 2001;166:2878-2886.

49. Yamamoto T, Yokozeki H, Nishioka K. Clinical analysis of 21 patients with psoriasis arthropathy. J Dermatol. 2005;32:84-90.

50. Costello P, Bresnihan B, O'Farrelly C, FitzGerald O. Predominance of CD8+ T lymphocytes in psoriatic arthritis. J Rheumatol. 1999;26: 1117-1124.

51. Partsch G, Wagner E, Leeb BF, Bröll H, Dunkey A, Smolen JS. T cell derived cytokines in psoriatic arthritis synovial fluids. Ann Rheum Dis. 1998;57:691-693.

52. van Kuijk AW, Reinders-Blankert P, Smeets TJ, Dijkmans BA, Tak PP. Detailed analysis of the cell infiltrate and the expression of mediators of synovial inflammation and joint destruction in the synovium of patients with psoriatic arthritis: implications for treatment. Ann Rheum Dis. 2006;65:1551-1557.

53. Noordenbos T, Yeremenko N, Gofita I, et al. Interleukin-17-positive mast cells contribute to synovial inflammation in spondylarthritis. Arthritis Rheum. 2012;64:99-109.

54. Raychaudhuri SP, Raychaudhuri SK, Genovese MC. IL-17 receptor and its functional significance in psoriatic arthritis. Mol Cell Biochem. 2012;359:419-429.

55. Wolk K, Witte E, Wallace E, et al. IL-22 regulates the expression of genes responsible for antimicrobial defense, cellular differentiation, and mobility in keratinocytes: a potential role in psoriasis. Eur J Immunol. 2006;36:1309-1323

56. Keijsers RR, Joosten I, van Erp PE, Koenen HJ, van de Kerkhof PC. Cellular sources of IL-17 in psoriasis: a paradigm shift? Exp Dermatol. 2014;23:799-803.

57. Fearon U, Griosios K, Fraser A, et al. Angiopoietins, growth factors, and vascular morphology in early arthritis. J Rheumatol. 2003;30: 260-268.

58. Yamamoto T. Angiogenic and inflammatory properties of psoriatic arthritis. ISRN Dermatol. 2013;2013:630620.

59. Partsch G, Steiner G, Leeb BF, Dunky A, Bröll H, Smolen JS. Highly increased levels of tumor necrosis factor-alpha and other proinflammatory cytokines in psoriatic arthritis synovial fluid. $J$ Rheumatol. $1997 ; 24: 518-523$. 
60. Partsch G, Wagner E, Leeb BF, Dunky A, Steiner G, Smolen JS. Upregulation of cytokine receptors sTNF-R55, sTNF-R75, and sIL-2R in psoriatic arthritis synovial fluid. J Rheumatol. 1998;25:105-110.

61. Spadaro A, Rinaldi T, Riccieri V, Valesini G, Taccari E. Interleukin 13 in synovial fluid and serum of patients with psoriatic arthritis. Ann Rheum Dis. 2002;61:174-176.

62. Veale DJ, Ritchlin C, FitzGerald O. Immunopathology of psoriasis and psoriatic arthritis. Ann Rheum Dis. 2005;64 Suppl 2:ii26-ii29.

63. Leibovich SJ, Polverini PJ, Shepard HM, Wiseman DM, Shively V, Nuseir N. Macrophage-induced angiogenesis is mediated by tumor necrosis factor-alpha. Nature. 1987;329:630-632.

64. Colucci S, Brunetti G, Cantatore FP, et al. Lymphocyte and synovial fluid fibroblasts support osteoclastogenesis through RANKL, TNFalpha, and IL-7 in an in vitro model derived from human psoriatic arthritis. J Pathol. 2007;212:47-55.

65. Ritchlin CT, Haas-Smith SA, Li P, Hicks DG, Schwarz EM. Mechanisms of TNF-alpha- and RANKL-mediated osteoclastogenesis and bone resorption in psoriatic arthritis. J Clin Invest. 2003;111:821-831.

66. Yago T, Nanke Y, Kawamoto M, et al. IL-23 indices human osteoclastogenesis via IL-17 in vitro, and anti-IL-23 antibody attenuates collagen-induced arthritis in rats. Arthritis Res Ther. 2007;9:R96.

67. Chen L, Wei XQ, Evans B, Jiang W, Aeschlimann D. IL-23 promotes osteoclast formation by up-regulation of receptor activation of NFkappaB (RANK) expression in myeloid precursor cells. Eur J Immunol. 2008;38:2845-2854.

68. ten Dijke P, Krause C, de Gorter DJ, Lowik CW, van Bezooijen RL. Osteocyte-derived sclerosin inhibits bone formation: its role in bone morphogenetic protein and Wnt signaling. J Bone Joint Surg Am. 2008; 90 Suppl 1:31-35.

69. Diarra D, Stolina M, Polzer K, et al. Dickkopf-1 is a master regulator of joint remodeling. Nat Med. 2007;13:156-163.

70. Chen D, Zhao M, Mundy GR. Bone morphogenetic proteins. Growth Factors. 2004;22:233-241.

71. Rahimi H, Ritchlin CT. Altered bone biology in psoriatic arthritis. Curr Rheumatol Rep. 2012;14:349-357.
72. Mease PJ, Armstrong AW. Managing patients with psoriatic disease: the diagnosis and pharmacologic treatment of psoriatic arthritis in patients with psoriasis. Drugs. 2014;74:423-441

73. Rose S, Toloza S, Bautista-Molano W, Helliwell PS; GRAPPA Dactylitis Study Group. Comprehensive treatment of dactylitis in psoriatic arthritis. J Rheumatol. 2014;41:2295-2300.

74. Ritchlin CT, Kavanaugh A, Gladman DD, et al. Treatment recommendations for psoriatic arthritis. Ann Rheum Dis. 2009;68: 1387-1394.

75. Mease PJ, Gladman DD, Ritchlin CT, et al. Adalimumab for the treatment of patients with moderately to severely active psoriatic arthritis: results of a double-blind, randomized, placebo-controlled trial. Arthritis Rheum. 2005;52:3279-3289.

76. Antoni CE, Kavanaugh A, Kirkham B, et al. Sustained benefits of infliximab therapy for dermatologic and articular manifestations of psoriatic arthritis: results from the infliximab multinational psoriatic arthritis controlled trial (IMPACT). Arthritis Rheum. 2005;52: 1227-1236.

77. Kavanaugh A, van der Heijde D, McInnes IB, et al. Golimumab in psoriatic arthritis: one-year clinical efficacy, radiographic, and safety results from a phase III, randomized, placebo-controlled trial. Arthritis Rheum. 2012;64:2504-2517.

78. McInnes IB, Kavanaugh A, Gottlieb AB, et al. Efficacy and safety of ustekinumab in patients with active psoriatic arthritis: 1 year results of the phase 3, multicentre, double-blind, placebo-controlled PSUMMIT 1 trial. Lancet. 2013;382:780-789.

79. McInnes IB, Sieper J, Braun J, et al. Efficacy and safety of secukinumab, a fully human anti-interleukin-17A monoclonal antibody, in patients with moderate-to-severe psoriatic arthritis: a 24-week, randomized, double-blind, placebo-controlled, phase II proof-of-concept trial. Ann Rheum Dis. 2014;73:349-356.

80. Kavanaugh A, Mease PJ, Gomez-Reino JJ, et al. Treatment of psoriatic arthritis in a phase 3 randomised, placebo-controlled trial with apremilast, an oral phosphodiesterase 4 inhibitor. Ann Rheum Dis. 2014;73: 1020-1026.
Open Access Rheumatology Research and Reviews

\section{Publish your work in this journal}

Open Access Rheumatology Research and Reviews is an international, peer-reviewed, open access journal, publishing all aspects of clinical and experimental rheumatology in the clinic and laboratory including the following topics: Pathology, pathophysiology of rheumatological diseases; Investigation, treatment and management of rheumatological

\section{Dovepress}

diseases; Clinical trials and novel pharmacological approaches for the treatment of rheumatological disorders. The manuscript management system is completely online and includes a very quick and fair peerreview system, which is all easy to use. Visit http://www.dovepress.com/ testimonials.php to read real quotes from published authors. 